\title{
Environmental factors shaping the diversity of bacterial communities that promote rice production
}

\author{
Zhaohui Wu' ${ }^{1 \dagger}$, Qingshu Liü ${ }^{2,3 \dagger}$, Zhenyu Li ${ }^{4}$, Wei Cheng ${ }^{2}$, Jimin Sun ${ }^{5}$, Zhaohui Guo ${ }^{2}$, Yongmei Li ${ }^{2}$, Jianqun Zhou ${ }^{6}$,
} Delong Meng ${ }^{4}$, Hongbo $\mathrm{Li}^{7}$, Ping Lei ${ }^{2^{*}}$ and Huaqun Yin ${ }^{4^{*}}$ (D)

\begin{abstract}
Background: Exploiting soil microorganisms in the rhizosphere of plants can significantly improve agricultural productivity; however, the mechanism by which microorganisms specifically affect agricultural productivity is poorly understood. To clarify this uncertainly, the rhizospheric microbial communities of super rice plants at various growth stages were analysed using $16 \mathrm{~S}$ rRNA high-throughput gene sequencing; microbial communities were then related to soil properties and rice productivity.

Results: The rhizospheric bacterial communities were characterized by the phyla Proteobacteria, Acidobacteria, Chloroflexi, and Verrucomicrobia during all stages of rice growth. Rice production differed by approximately $30 \%$ between high- and low-yield sites that had uniform fertilization regimes and climatic conditions, suggesting the key role of microbial communities. Mantel tests showed a strong correlation between soil conditions and rhizospheric bacterial communities, and microorganisms had different effects on crop yield. Among the four growing periods, the rhizospheric bacterial communities present during the heading stage showed a more significant correlation $(p<0.05)$ with crop yield, suggesting their potential in regulating crop production. The biological properties (i.e., microbes) reflected the situation of agricultural land better than the physicochemical characterics (i.e., nutrient elements), which provides theoretical support for agronomic production. Molecular ecological network (MEN) analysis suggested that differences in productivity were caused by the interaction between the soil characteristics and the bacterial communities.
\end{abstract}

Conclusions: During the heading stage of rice cropping, the rhizospheric microbial community is vital for the resulting rice yield. According to network analysis, the cooperative relationship (i.e., positive interaction) between between microbes may contribute significantly to yield, and the biological properties (i.e., microbes) better reflected the real conditions of agricultural land than did the physicochemical characteristics (i.e., nutrient elements).

Keywords: Bacterial diversity, Bacterial community structure, Super hybrid rice, 16S rRNA pyrosequencing technology, Crop yield, Soil physicochemical properties

\section{Background}

Recent studies have suggested that modern agriculture will face substantial challenges over the coming decades [1], and the market demand for agricultural products will increase by at least $70 \%$ to 2050 [2]. Over the last few decades, improper agricultural production methods,

\footnotetext{
*Correspondence: hnwsw@263.net.cn; yinhuaqun_cs@sina.com

'Zhaohui Wu and Qingshu Liu contributed equally to this work.

${ }^{2}$ Hunan Institute of Microbiology, Changsha 410009, China

${ }^{4}$ School of Minerals Processing and Bioengineering, Central South University, Changsha 410083, China

Full list of author information is available at the end of the article
}

e.g. the improper use of chemical fertilizers and pesticides [3], have triggered a series of environmental problems [4, 5]. Numerous studies have addressed sustainability issues, and one recommended approach is exploiting the soil microorganisms [2] to sustainably meet agricultural demands [6]. Soil microorganisms play important roles in agriculture, particularly in the nutrient supply and in the biocontrol of plant disease [7, 8]. Rhizospheric microorganisms exist within a narrow zone around the root of a plant and are found at densities of approximately $10^{11}$ cells per gram [9]; additionally, these microorganisms, are considered as the

(c) The Author(s). 2018 Open Access This article is distributed under the terms of the Creative Commons Attribution 4.0 International License (http://creativecommons.org/licenses/by/4.0/), which permits unrestricted use, distribution, and 
plant's second genome [10]. The rhizospheric microbial community structure is mainly mediated by root exudate (e.g., sugars, amino acids, siderophores, and enzymes) [11]. Therefore, the interaction between plant roots and rhizospheric microorganisms potentially influences ecosystem functioning by promoting the circulation of materials [12].

Complex biochemical processes occur between rhizospheric microorganisms and plants, and microorganisms enhance soil fertility [13-15], maintain below-ground ecological structure and are associated with plant health (e.g., diseases, pathogens and weed suppression) [16]. Microbial diversity is also an indicator of soil microorganisms in a region [17], which provide a vast amount of ecological information in terms of the soil. Although the relationships between the soil microbial diversity and the functioning and sustainability of agricultural ecosystems have not been fully elucidated $[18,19]$, it is accepted that microbial diversity plays an important role in agricultural production [20, 21]. Microbial diversity includes the range of microorganisms and their relative abundance in natural habitats [22]. In addition to microbial diversity, microbial community structure also responds to the basis of agroecosystem services in agricultural production [23]. Soil microbial communities drive globally important processes [24], including elemental cycles and energy flows. These microbial communities are involved in various processes that serve essential functions in agricultural production [25] by promoting crop absorption of nutrients and inhibiting harmful pathogens [7, 8, 26-28]. For example, soil microbes can promote plant growth through the degradation of manure fertilizers and form humus nutrients, which are then easily absorbed by plants. Other microorganisms may regulate soil $\mathrm{pH}$, generating favourable conditions that permit functional microorganisms to work at full capacity and promote production [29]. This kind of microorganism often plays a crucial role in the agricultural ecosystem. Explaining the direct effects of soil microbial communities on crop-growth and yield is challenging because the ecosystem functions provides by most soil microorganisms are not well clear [30, 31]. Numerous studies have shown dramatically related results that indicate soil community structure is characterized by Proteobacteria, Acidobacteria, Actinobacteria, Bacteroidetes, Firmicutes, etc. Nevertheless, further consideration of the interactions between the microbial communities and the external environment has identified biological and abiotic factors related to crop yield. Some studies have associated the soil microbial properties with the transformation of edaphic nutrients, which have an essential role in plant growth that helps obtain high yields $[10,32]$. However, the innate mechanism of how microorganisms specifically affect crop productivity is poorly understood, and our study is devoted to statistically explaining the links between them.

In the process of production, we found a gap (more than $30 \%$ ) in crop production between different super rice cultivation types with similar, fertilisation regimes and latitudinal and longitudinal positions. Highthroughput sequencing methods served to collect rhizospheric microbial community information in soils. The relationship between soil physicochemical attributes and rhizospheric microorganisms at different stage (from pre-transplanting to the ripening stage) of the super hybrid rice "Y Liang You 900" was investigated to reveal the inborn mechanism of how microorganisms specifically affect crop productivity. We mainly explored the interaction of microbial communities. By comparing the differences between soil microorganisms in high- and low-yield areas during discrete periods, we explored the mechanism of how microorganisms specifically affect agricultural productivity based on soil characteristics. Our study concluded that (1) it is possible improve the average crop yield by controlling rational agricultural management in the heading stage, (2) the positive species interactions within communities may contribute to crop yield, and(3) the biological properties (i.e., microbes) were better than the physicochemical characteristics (i.e., nutrient elements) in terms of reflecting the actual situation of agricultural land.

\section{Methods}

\section{Study sites and sampling}

Soil samples were collected from Xupu $\left(110^{\circ} 31^{\prime} \mathrm{E}, 27^{\circ} 23^{\prime} \mathrm{N}\right.$, $\mathrm{Ha})$, Ningxiang $\left(112^{\circ} 16^{\prime} \mathrm{E}, 28^{\circ} 08^{\prime} \mathrm{N}\right.$, Ly), LonghuiZhaojiachong $\left(110^{\circ} 56^{\prime} \mathrm{E}, 27^{\circ} 27^{\prime} \mathrm{N}, \mathrm{Hb}\right)$ and LonghuiNiuxingzui $\left(110^{\circ} 56^{\prime} \mathrm{E}, 27^{\circ} 29^{\prime} \mathrm{N}, \mathrm{Hc}\right)$. The sites are paddy fields planted with "Y Liang You 900" super hybrid rice. Sampling was conducted on private land, and the land owner gave permission for our sampling activity. For all sites, the fertilization regime was the same and rice was harvested in October, 2014. The rice yield was calculated according to Chen et al. [33]. Rhizospheric soil samples were collected at four rice development stages: pretransplanting stage $(0$ weeks), tillering stage (6 weeks), heading stage (14 weeks), and ripening stage (20 weeks). When sampling, three biological replicates were sampled from each site, resulting in a total of 48 samples (4 stages $\times$ 4 sites $\times 3$ replicates $=48$ samples, also see in Additional file 1: Table S2). Rhizosphere soils were sampled according to Smalla et al. [34]. After sampling, soil samples were separated into two parts, one part was air dried and stored at $4{ }^{\circ} \mathrm{C}$ until physiochemical analysis and the other part was frozen in liquid nitrogen and stored at $-80{ }^{\circ} \mathrm{C}$ until molecular analysis. 
The yields of super hybrid rice "Y Liang You 900" from four sampling sites are presented in Additional file 1: Table S1. Based on the rice yield, the sites were referred to as 'low-yield' sites (Ly, $1.074 \mathrm{~kg} / \mathrm{m}^{2}$ ) and 'highyield' sites ( $\mathrm{Ha}, 1.543 \mathrm{~kg} / \mathrm{m}^{2} ; \mathrm{Hb}, 1.517 \mathrm{~kg} / \mathrm{m}^{2}$; and $\mathrm{Hc}$, $\left.1.589 \mathrm{~kg} / \mathrm{m}^{2}\right)$. The yield of 'high-yield' sites was approximately $30 \%$ higher than the yield of the 'lowyield' site.

\section{Soil properties}

Soil $\mathrm{pH}$ was measured using a $\mathrm{pH}$ metre and by dissolving $5 \mathrm{~g}$ of each soil sample in $25 \mathrm{~mL}$ of distilled water. The nitrogen contents, including total nitrogen (TN) and available nitrogen (AN), were determined by the Kjeldahl procedure [35]. Phosphorus (P) was determined photo metrically as orthophosphate with using a vanado-molybdate method [36], and potassium (K) was determined using inductively coupled plasma-atomic emission spectroscopy (ICP-AES) [37]. Additionally, soil organic matter (SOM) was analysed using the potassium dichromate method by titration with ammonium ferrous sulphate (i.e., Mohr's salt solution) [38].

\section{DNA extraction, PCR amplification and MiSeq sequencing}

The soil samples were homogenized in liquid nitrogen and mixed completely, and $1 \mathrm{~g}$ of each soil sample was used for DNA extraction. Soil microbial genomic DNA was extracted using a soil microbial DNA extraction kit (MOBIO, San Diego, USA). The hyper-variable region (V4) of prokaryotic 16S rRNA [39] was amplified using the primer pair 515F (5'-GTGCCAGCMGCCGCGGTAA-3') and 806R (5'-GGACTACHVGGTWTCTAAT3 ) [31]. PCR products were recovered and the quality and quantity of recovered PCR products was determined using a Nano-drop spectrophotometer (Thermo Fisher Scientific, Waltham, MA, USA). Purified PCR products were subjected to the MiSeq platform (Illumina, San Diego, CA) with a 500-cycle kit ( $2 \times 250$ bp paired-ends) for sequencing. Data processing was conducted according to Tao et al. [40] and Yin et al. [41]. Specifically, reads were assigned to different samples according to the barcode sequence and primers were removed. The left and right reads were then merged with a minimum of $10 \mathrm{bp}$ overlap and less than $5 \%$ mismatches using Flash [42]. Ambiguous bases $(\mathrm{N})$ were removed from the merged sequences and chimers were removed by Uchim [43]. Finally, high-quality sequences were clustered using UCLUST [44] at 97\% similarity level [45], and the OTU table was constructed after removing the false positive sequences (singletons). Taxa assignment was carried out by blasting the sequences to the RDP database [46] with $50 \%$ confidence. The rarefaction curve is shown in Additional file 1: Figure S1. To reduce the variations caused by different sequencing depth, sequencing depths was rarefied to16, 000 for all samples and the rarefied OTU table was used for all downstream analyses. All sequences were submitted to the NCBI database under the accession number SRP083104.

\section{Statistical analysis}

Soil microbial diversity indices, including the Shannon Wiener, Inverse Simpson, and Pielou evenness indices, were calculated using the $\mathrm{R}$ version 3.3.2 (https://www.rproject.org/) platform with the package vegan 2.4.2. [47]. Detrended correspondence analysis (DCA) for detecting the variation in microbial community composition among sites/stages was also performed using the vegan package. Permutational multivariate analysis of variance (Adonis) was used to test the effects of soil variables on crop yield. Standard and Mantel tests were carried out to identify the correlations between environmental factors and soil bacterial communities (based on Euclidean distance). The relationship between soil properties and microbial microorganisms in the heading stage was further analysed by the PLSPM model (partial least-squares path) using the plspm package [48]. Additional statistical analysis including one-way ANOVA and Pearson correlation analysis was also completed using $\mathrm{R}$ version 3.3.2, and a $p$ value less than 0.05 was considered significant. A molecular ecological network (MEN) using an RMTbased network approach was built on the IEG website (http://ieg4.rccc.ou.edu/) to investigate the interaction between microbes [49-51] and the networks; finally, the result were visualized using Cytoscape 3.4.0.

\section{Results}

\section{Soil properties}

The $\mathrm{pH}$ varied from 4 to 7 (Additional file 1: Table S3), and the lowest $\mathrm{pH}$ was at the Ly site. The Ly site had a lower concentration of soil nutrients $(\mathrm{N}, \mathrm{P}$, and $\mathrm{K})$ than the other sites; particularly, the SOM (soil organic matter) showed the largest difference between Ly and the high-yield sites. Permutational multivariate analysis of variance (Adonis) was conducted using three methods (Bray, Euclid and Horn), and analyses indicated that the rice yield was closely associated with the soil physiochemical properties (Additional file 1: Table S4). The DCA based on soil environmental factors (Fig. 1) showed the low-yield site had very different soil properties compared to the high-yield sites. Pearson correlation analysis showed various correlations between the rice yield and the soil properties (Additional file 1: Table S5). Among all soil properties, the available nitrogen (AN) and available potassium (AK) were significantly (Pearson correlation $>0.650 ; p<0.05)$ and positively associated with rice yield. In addition, TN, TP, and SOM were also significantly correlated $(p<0.05)$ with crop yield in all 


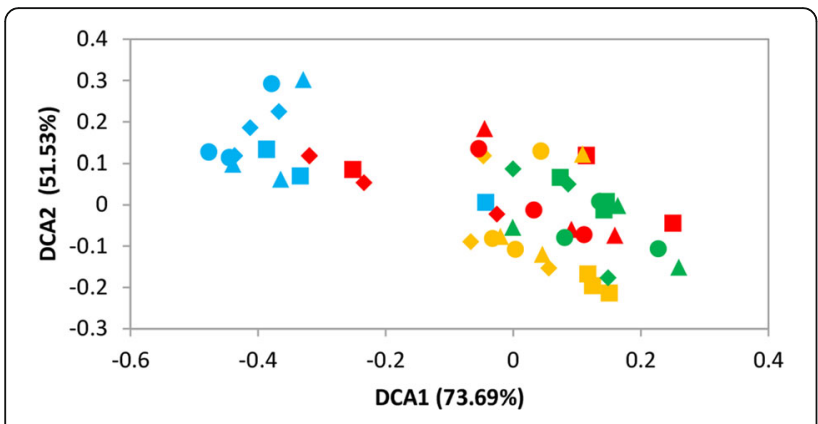

$\square \mathrm{Ha}-\mathrm{OP} \backsim \mathrm{Hb}-\mathrm{OP} \backsim \mathrm{Hc}-\mathrm{OP} \approx \mathrm{Ly}-\mathrm{OP} \diamond \mathrm{Ha}-2 \mathrm{P} * \mathrm{Hb}-2 \mathrm{P} \diamond \mathrm{Hc}-2 \mathrm{P} \bullet \mathrm{Ly}-2 \mathrm{P}$

$\triangle \mathrm{Ha}-3 \mathrm{P} \triangle \mathrm{Hb}-3 \mathrm{P} \triangle \mathrm{Hc}-3 \mathrm{P} \Delta \mathrm{Ly}-3 \mathrm{P} \bullet \mathrm{Ha}-4 \mathrm{P} \bullet \mathrm{Hb}-4 \mathrm{P} \bullet \mathrm{Hc}-4 \mathrm{P} \bullet \mathrm{Ly}-4 \mathrm{P}$

Fig. 1 Detrended correspondence analysis (DCA) of soil environmental factors with all samples from pre-transplanting stage to ripening stage

stages of development. Furthermore, pH was substantially correlated with yield during the tillering stage.

\section{Bacterial diversity}

The microbial community diversity indices, including Shannon and Simpson diversity and Pielou evenness were significantly higher in the high-yield sites than in the low-yield site, and generally, the diversity indices were the highest during the tillering stage. The diversity differed slightly between the pre-transplant and heading stages in the Ha and Hc sites; however, the bacterial diversity at the Ly site was similar during all stages of crop development. In addition, two-way ANOVA indicated that both stage and site had significant effects on microbial community diversity indices (Table 1). Pearson correlation showed the microbial community diversity during the pre-transplanting and heading stages was positively correlated $(p<0.05)$ with rice yield (Fig. 2). Adonis (permutational multivariate analysis of variance) also showed the microbial community during the pretransplanting stage and the heading stage had a significant effect on crop yield (Additional file 1: Table S6), whereas the tillering and ripening stages did not show significant effects.

\section{Network analysis on relationships between key microbial communities}

To explore the interactions between rhizospheric microbes, RMT-based molecular ecological networks (MEN) were constructed and analysed. All sites had similar RMT thresholds $(0.88 \sim 0.90)$. However, the number of nodes and links was lower in the Ly site than in the other sites (Figs. 3 and 4, Additional file 1: Figures S2 and S3). There were more positive interactions between OTUs in the high-yield site ( $\mathrm{Ha}, \mathrm{Hb}$ and $\mathrm{Hc}$ ) network than that in the

Table 1 Rhizospheric microbial community diversity at different developmental stages at four sites

\begin{tabular}{|c|c|c|c|}
\hline & Shannon diversity & Simpson & Pielou evenness \\
\hline Ha_Op & $7.01 \pm 0.08 \mathrm{abcde}$ & $0.9971 \pm 0.0005 \mathrm{ab}$ & $347.61 \pm 60.66 \mathrm{abcd}$ \\
\hline Ha_2p & $7.28 \pm 0.11 a$ & $0.9981 \pm 0.0004 a$ & $553.05 \pm 116.91 a$ \\
\hline $\mathrm{Ha}$ _3p & $7.08 \pm 0.03 \mathrm{abcd}$ & $0.9976 \pm 0.0005 \mathrm{ab}$ & $421.17 \pm 78.66 \mathrm{abcd}$ \\
\hline Ha_4p & $6.77 \pm 0.05 e$ & $0.9948 \pm 0.0026 b$ & $223.77 \pm 95.43 d$ \\
\hline Hb_Op & $7.05 \pm 0.13 \mathrm{abcde}$ & $0.9978 \pm 0.0006 a b$ & $488.8 \pm 131.09 a b c$ \\
\hline $\mathrm{Hb} \_2 \mathrm{p}$ & $7.28 \pm 0.06 a$ & $0.9983 \pm 0.0002 \mathrm{a}$ & $583.58 \pm 62.07 a$ \\
\hline Hb_3p & $7.19 \pm 0.06 a b$ & $0.9982 \pm 0.0001 a$ & $548.53 \pm 21.6 a b$ \\
\hline $\mathrm{Hb} \_4 \mathrm{p}$ & $7.17 \pm 0.01 \mathrm{abc}$ & $0.9982 \pm 0.0001 a$ & $551.81 \pm 16.64 a b$ \\
\hline Hc_Op & $7.03 \pm 0.1 \mathrm{abcde}$ & $0.9977 \pm 0.0003 \mathrm{ab}$ & $442.72 \pm 61.61 \mathrm{abcd}$ \\
\hline $\mathrm{Hc} \_2 \mathrm{p}$ & $7.07 \pm 0.17 \mathrm{abcde}$ & $0.9975 \pm 0.0009 a b$ & $427.48 \pm 139.1 \mathrm{abcd}$ \\
\hline Hc_3p & $7.05 \pm 0.14 \mathrm{abcde}$ & $0.9977 \pm 0.0005 \mathrm{ab}$ & $453.29 \pm 85.08 \mathrm{abcd}$ \\
\hline Hc_4p & $6.87 \pm 0.13 \mathrm{cde}$ & $0.9969 \pm 0.0005 \mathrm{ab}$ & $328.54 \pm 58.07 \mathrm{bcd}$ \\
\hline Ly_Op & $6.86 \pm 0.12 \mathrm{de}$ & $0.9962 \pm 0.0012 \mathrm{ab}$ & $277.73 \pm 73.87 \mathrm{bcd}$ \\
\hline Ly_2p & $6.94 \pm 0.1 \mathrm{bcde}$ & $0.9971 \pm 0.0007 \mathrm{ab}$ & $363.47 \pm 92.08 \mathrm{abcd}$ \\
\hline Ly_3p & $6.9 \pm 0.11 \mathrm{bcde}$ & $0.9957 \pm 0.0021 \mathrm{ab}$ & $264.65 \pm 101.48 \mathrm{bcd}$ \\
\hline Ly_4p & $6.84 \pm 0.04 \mathrm{de}$ & $0.996 \pm 0.001 \mathrm{ab}$ & $257.85 \pm 56.84 \mathrm{~cd}$ \\
\hline Two-way ANOVA & Shannon & Simpson & Pielou evenness \\
\hline Site effect & $<0.001$ & 0.001 & $<0.001$ \\
\hline Stage effect & $<0.001$ & 0.034 & $<0.001$ \\
\hline Cross effect & 0.026 & 0.182 & 0.082 \\
\hline
\end{tabular}

Op: pre-transplanting stage; $2 \mathrm{p}$ : tillering stage; $3 \mathrm{p}$ : heading stage; and $4 \mathrm{p}$ : ripening stage. The results are shown as the means and S.D. of three biological replicates. Values that do not share letters are different at the $p<0.05$ level following Tukey's t-test. Site, stage and cross effects were accessed by two-way ANOVA 

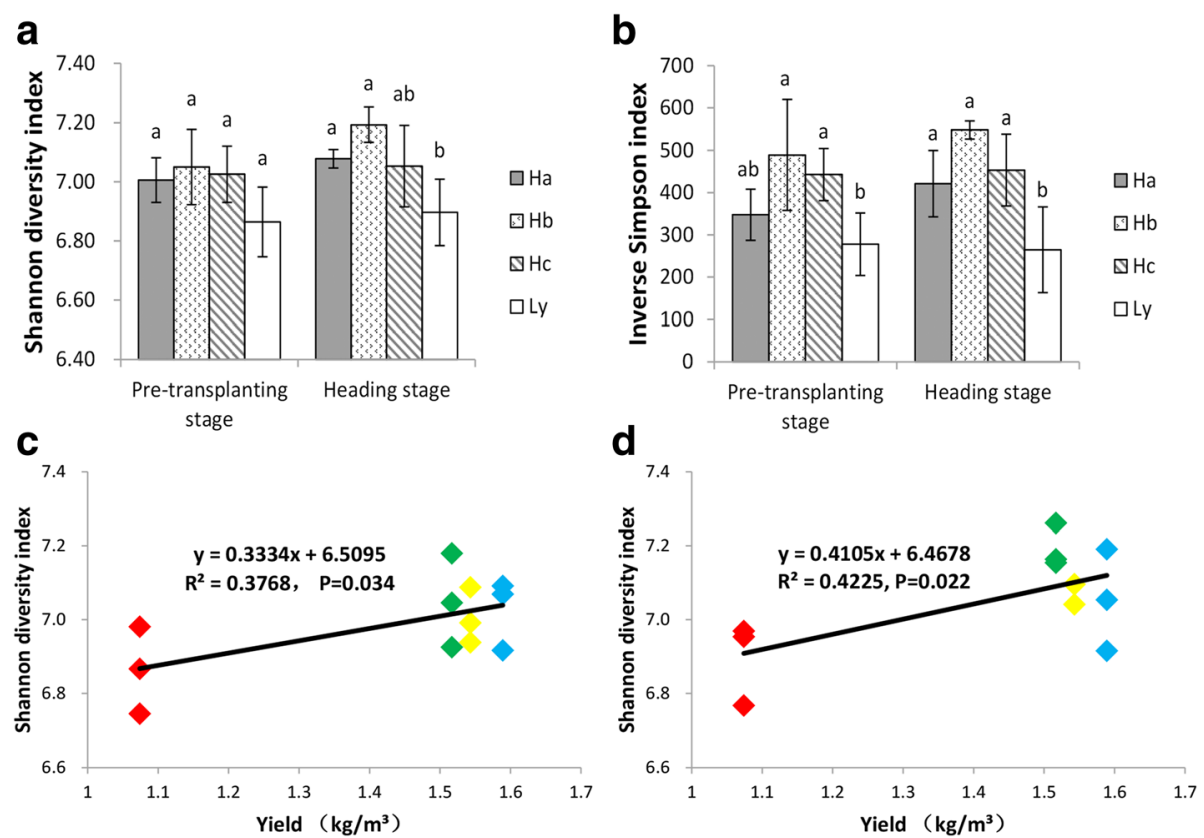

Fig. 2 Dcomparing the differences in microbial diversity indices was carried out by one-way analysis of variance (ANOVA) before the transplanting and heading stages. Error bars are based on the standard error and different lowercase letters indicate significant differences at the level of 0.05 as indicated by the ANOVA results. (a): Shannon Wiener index; (b): Inverse Simpson index; (c)Linear regression analysis of the relationship between crop yield and Shannon Wiener diversity index during pre-transplanting stage; and (d) Linear regression analysis of the relationship between crop yield and Shannon Wiener diversity index at the heading stage

low-yield site (Ly) network. Nodes with high degrees in the Ly networks were classified into Bacteroides (OTU 1367 and OTU_742) and Proteobacteria (OTU_807 and OTU_275), while in high-yield site networks, nodes with high degree were classified into Acidobacteria, Actinobacteria and Planctomycete. In addition, site $\mathrm{Hb}$ had the most complicated network (Additional file 1: Figure S3) with the most links and the maximal degree, presenting more intricate topological properties than the other sites.

\section{Microbial community composition and structure}

All sequences were clustered into 14,332 operational taxonomic units (OTUs) and were assigned into 469 genera. The permutational multivariate analysis of variance (Adonis) from three methods (Bray, Euclid and Horn) at the OTUs (Additional file 1: Table S7) and the genus level (Additional file 1: Table S8) showed that the microbial community structure during the heading stage was closely associated with the yield. A venn diagram (Fig. 5c and Additional file 1: Figure S4) showed there were 87 OTUs shared by sites $\mathrm{Ha}, \mathrm{Hb}$, and $\mathrm{Hc}$ during the pre-transplanting stage, but this was not found at the Ly site. During the crop-growth period, 184 OTUs were shared by high-yield sites. Whereas the number of shared OTU taxa in the four sites reduced from 600 during the pre-transplanting stage to 370 during the crop-growth period. The number of unique OTUs in site
Ly and the other sites increased when the stage changed from the pre-transplanting stage to the heading stage (Fig. 5d). An increase in unique OTUs in site Ly indicated that the difference between high- and low-yield sites increased. Detrended correspondence analysis (DCA) showed that the microbial community structure differed more substantially during three of the cropgrowth stages than in the pre-transplanting stage (Fig. $5 \mathrm{a}$ and b; Additional file 1: Figure S4c and d). Furthermore, the community structure differences between the low- and high-yield sites were most obvious during the heading stage; therefore, we focused on the rhizospheric microbial community during the heading stage (Additional file 1: Table S9). Proteobacteria, Acidobacteria, and Chloroflexi were the most abundant phyla found in the rhizospheric microbial community during the heading stage (Additional file 1: Table S9a), and each accounted for more than $10 \%$ of the community. At the class level, Deltaproteobacteria was the most abundant class in all samples, and was followed by Anaerolineae, Betaproteobacteria, Alphaproteobacteria. (Additional file 1: Table S9b).

\section{Relationship between soil characteristics, microorganisms} and crop yield

Mantel tests were carried out to determine the correlations between the soil physical and chemical properties 

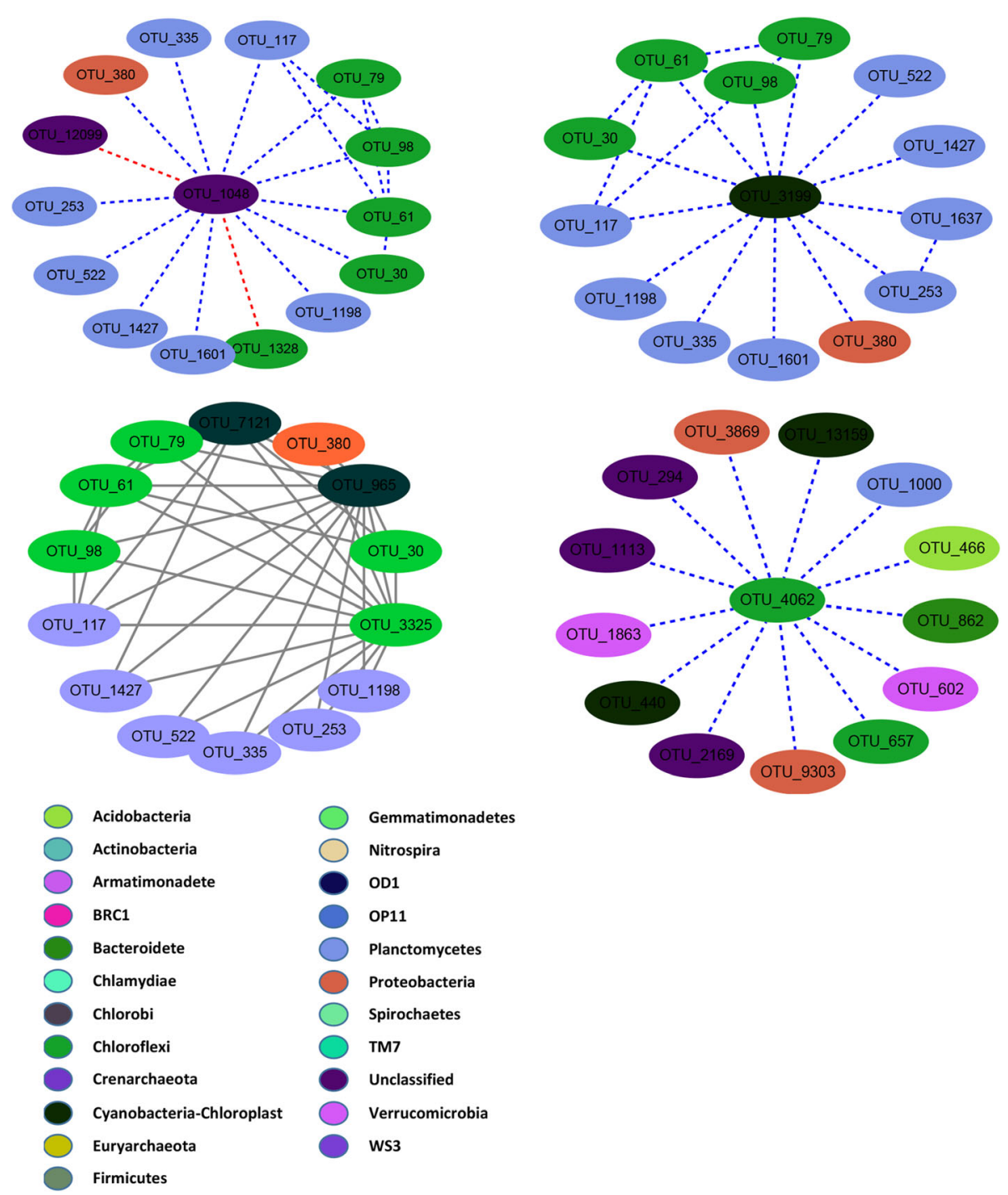

Fig. 3 Network constructed by thethe highest level (highly degree) of bacterial communities at site Hc. Each node signifies an OTU that could corresponds to a microbial population. Colours of the nodes indicate different major phyla. Blue and red lines represent positive and negative path coefficients, respectively

and the soil microorganisms [52] (Table 2). The results indicated that soil conditions had a significant influence on the bacterial community structure $(p<0.05)$ during the pre-transplanting and heading stages. During the heading stage, there was a significantly negative correlation (Pearson correlation $=-0.647 ; p<0.05$, Additional file 1: Table S10) between the yield and Crenarchaeota (Additional file 1: Table S10). In addition, soil environmental factors, such as AK, had a significant negative correlation (Pearson correlation $=-0.666, p<0.05$; Additional file 1: Table S10) with Crenarchaeota, but a significant positive correlation with crop yield. Crop yield and AN were also significantly positively correlated (Pearson correlation $=0.668 ; p<0.05$; Additional file 1: Table S10). In addition, Proteobacteria and Bacteroidetes showed a significant positive correlation
(Pearson correlation $=0.743-0.752 ; p<0.01$; Additional file 1 : Table S10) with $\mathrm{pH}$, whereas Chloroflexi exhibited a significant negative correlation with $\mathrm{pH}$ (Pearson correlation $=-0$. 621; $p<0.05$, Additional file 1: Table S10). Overall, $\mathrm{pH}$ showed significant effects on constraining the bacterial community.

Further analyses showed 17 phyla had significant effects on soil fertility and crop production. Some genera had significant impact on soil fertility as shown in Additional file 1: Table S11. The genera Geobacter, Syntrophorhabdus, Phaselicystis, Thiobacter, and Chondromyces (in addition to Cystobacter) of the phylum Proteobacteria, had negative impacts on crop yield. However, the abundance of the Proteobacteria was positively correlated with soil fertility. This also stressed that 


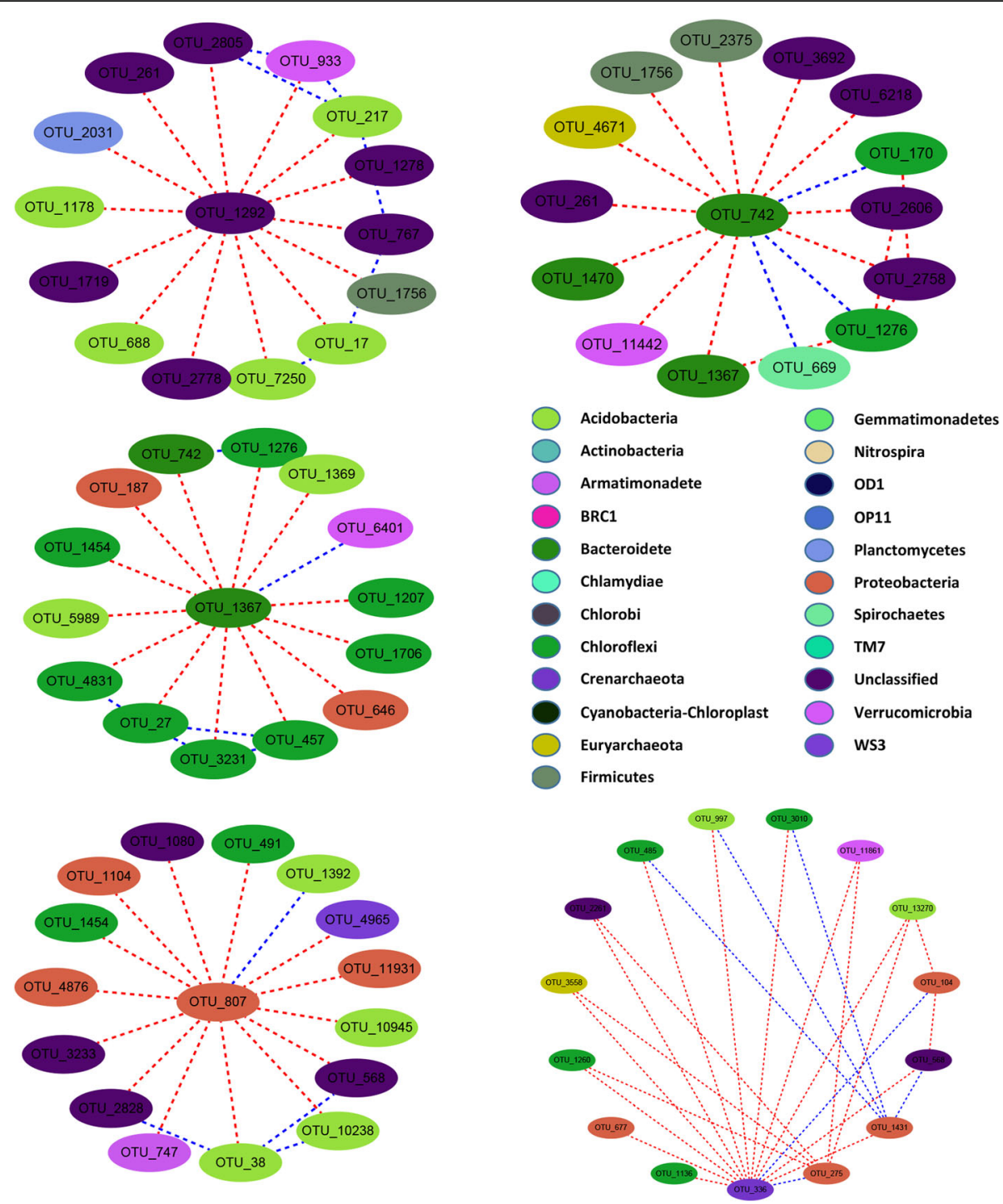

Fig. 4 Network constructed by thethe highest level (highly degree) of bacterial communities in site Ly. Each node signifies an OTU that corresponds to a microbial population. Colours of the nodes indicate different major phyla. Blue and red lines represent positive and negative path coefficients, repectively

the structure and function of the bacterial community was diverse and complex at the phylum level. Armatimonadetes-gp2 and Armatimonadetes-gp5 in Armatimonadetes showed contradictory correlation with soil fertility and crop production. Gp17, Gp6, Gp24, and Gp25, which belong to Acidobacteria, were significantly corelated with production. Spartobacteria incertae sedis in Verrucomicrobia, and OD1-sedis in OD1 showed diverse effects on crop yield. Therefore, the overall effect could be directly observed at the phylum level, as well as on a more precise level when considering the individual effects of each bacterial community at the genus level.

The partial least squares path model (PLSPM, Fig. 6) showed an association between the yield and soil biological and abiotic factors, in general, at the heading stage.
The bacterial diversity and the major bacterial communities were substantially related to the yield of super rice, but the structure of the bacterial communities was insignificant. The main soil factors affecting the yield of super rice were $\mathrm{pH}$ and SOM, which were also closely associated with the structure of soil bacterial communities. The goodness of fit to the model was 0.702 (>0.350), which validates the result and provides a reference value for our study.

\section{Discussion}

Relationship between rhizospheric microbial community and rice productivity

Crop productivity was mainly affected by the flow of energy and material in the soil ecosystem which is driven by 
a

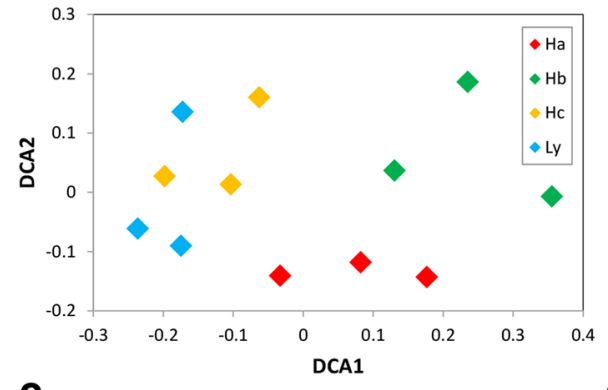

C

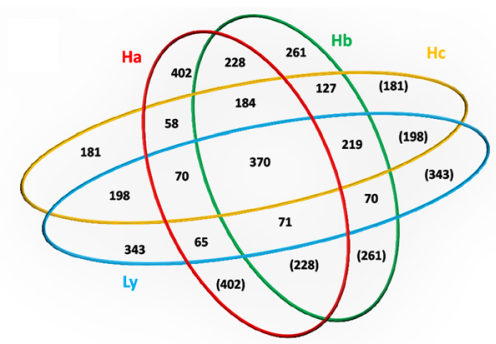

b

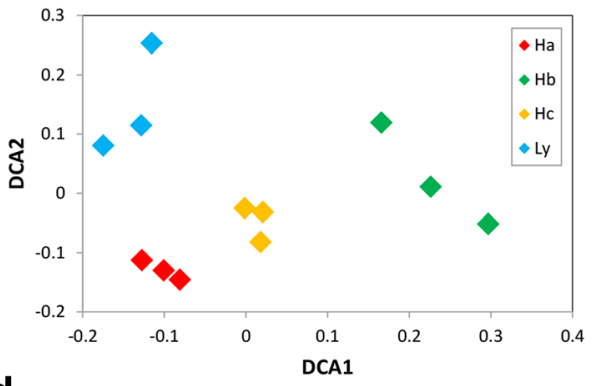

d

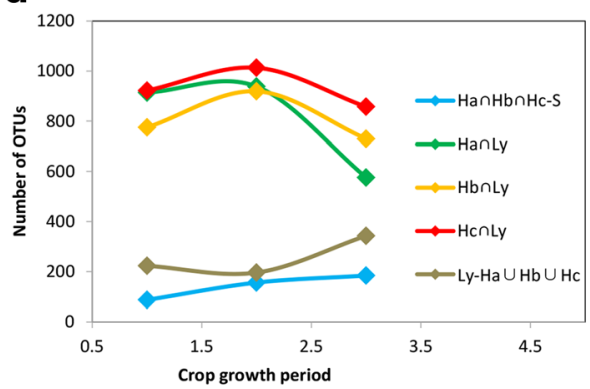

Fig. 5 Analsis of compositions and structures of bacterial communities from four groups. (a) Detrended correspondence analysis (DCA) of 16S rRNA gene sequencing data at the genus level during the tillering stage; (b) Detrended correspondence analysis (DCA) of 16S rRNA gene sequencing data at the genus level during the heading stage; (c) Venn diagrams were calculated by $\mathrm{R}$ with the package gplots and based on OTU level during the heading stage. Figures in pictures represent the taxa number of OTUs with common ownership at different sites; (d) Variation trends in OTUs under different classifications from pre-transplanting to heading stages. n: Intersection of mathematical symbol; $\mathrm{U}$ :Union mathematical symbol; and S: HanHbnHcnLy (intersection of four sites)

soil organisms. Microorganisms located in the plant's rhizosphere play pivotal roles in the soil geochemical cycle [53]. In the present study, the microbial community responded instantly to ecological changes during the pretransplanting and heading stages. Generally, the bacterial diversity was higher in the high-yield sites than in the lowyield site, which suggested that high bacterial diversity potentially increases the yield of super rice. This is because high bacterial diversity maintained a relatively stable ecosystem in the rhizosphere, which allowed effective nutrient cycling [54]. The difference in the microbial communities between the high-yield sites and the lowyield site may be a result of different nutrient levels in the soils. This was further supported by the Mantel test, which showed that the soil physiochemical properties had significant effects on the soil microbial communities. Resident plants shaped and restructured rhizospheric microbial communities via root exudates [55], which provides nutrients for microbial communities and regulated microbial diversity $[56,57]$. The ecosystem properties such as robustness and trophic interactions [58] were more stable in response to environmental fluctuations as diversity increased, for the richness of taxonomic diversity leads to the extension of niches and the utilization of resources. It is urgent to improve the stability and sustainability of farmland ecosystems [59], and meagre microbial diversity makes it difficult to resist the interference of detrimental factors. Additionally, a previous study by Laurent Philippot (2013) showed a loss in microbial diversity could affect nutrient cycling in soil [54], and microbial communities were closely related to material cycling.

\section{Rhizospheric microbial community was crucial for rice production in the heading stage}

The heading stage is a critical period for crop production; during this time, crops exhibit the most rapid

Table 2 Pearson correlation between microbial community diversity and rice yield

\begin{tabular}{lllll}
\hline Pearson & Yield & & & \\
\cline { 2 - 5 } correlation & Before transplanting & Tillering stage & Heading stage & 0.197 \\
\hline Shannon.Wiener & $0.614^{*}$ & $0.613^{*}$ & $0.650^{*}$ & 0.286 \\
Simpson & $0.579^{*}$ & 0.485 & $0.720^{* *}$ & 0.182 \\
Pielou & $0.658^{*}$ & 0.477 & $0.594^{*}$ & Ripening stage \\
\hline
\end{tabular}

The stars indicate the significance level: *: $P<0.05,{ }^{* *}: P<0.01$ 


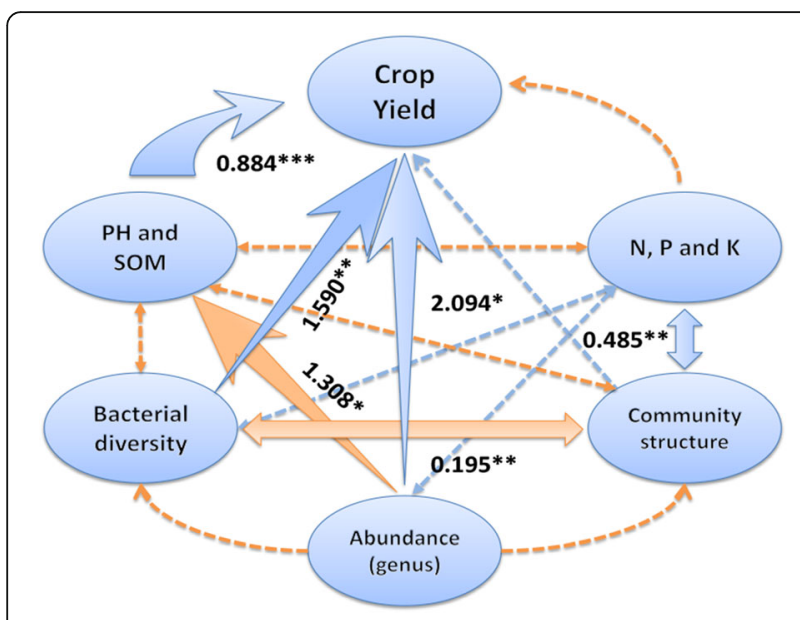

Fig. 6 Partial least squares path modelling (PLSPM) of the association between the yield of super rice and soil biological and abiotic factors during the heading stage. Goodness-of-fit of the model is 0.702. Blue and orange arrows represent positive and negative path coefficients, respectively. ${ }^{*} p<0.05,{ }^{* *} p<0.01,{ }^{* *} p<0.01$

growth and development of their entire life. It is a critical period for determining the amount of grains. During this stage, crops respond to external conditions [60]. Abundant nutrients, water, temperature, illumination, and other external conditions are required during this period, suggesting that this is an excellent time for farmers to increase production by means of topdressing. Soil fertility, a fundamental factor for plant growth, is mainly dependent on microbial transformations. Thus it is not surprising that the microbial community was most closely related to rice production during the heading stage. The association between the super rice with soil characteristics and the microbial microorganisms during the heading stage was further analysed using the PLSPM (partial least-squares path, Fig. 6). Bacterial communities such as Blastopirellula in the Planctomycete, are good indicators of soil fertility because the microorganisms respond to topdressing more rapidly than do the soil physicochemical characteristics [61], and microorganisms represent the true situation of the farmland; this is of great significance when establishing a stable and high-yield agricultural system. In the present study, some bacterial communities such as Chloroflexi, which do not produce oxygen during photosynthesis and have decreased nitrogen-fixation abilities, are abundant in soils; therefore, these bacteria are negatively correlated with the yield of super rice [62]. In contrast to detrimental bacteria, some bacterial communities, such as members of Acidobacteria, can degrade cellulose and adjust soil pH effectively [63, 64]; therefore, they are closely related to rice yield. However, the specific features of some Acidobacteria, e.g., GP6 and GP17, remain unclear.

\section{Effects of microbial species interactions on rice productivity}

Distinct sites had uniform fertilization regimes and similar climatic conditions, so the main difference in productivity was due to the rhizospheric microbial communities. In agricultural production, rhizospheric microorganisms are always associated with a considerable yield within a stable farmland ecosystem [65]. According to the molecular ecology networks, rhizospheric bacterial communities that played pivotal roles in the site Ly (Fig. 4), such as Bacteroidetes and Proteobacteria, are always classified as 'copiotrophs' (R-strategists), having a high growth rate in nutrient-rich conditions [66]. Owing to efficient metabolism in decomposing organic matter, the R-strategists should be chosen as the centre of communication among microbial communities, especially in artificially controlled nutrient-rich conditions. A farmland is a relatively complete ecosystem that keeps a dynamic balance between the input (contrived fertilizers) and output (plant growth) energetic processes; thus, due to rich resources leading to niche diversification and a reduction in the intensity of competition between cooccurring communities [57], the excellent decomposers and communicators with powerful metabolic rates, i.e., R-strategists, should present a positive role in the node of energy flows and material cycling. After all, cooccurrences may indicate a benign or mutually beneficial relationship. Conversely, the results showed that many R-strategists were negatively linked with their nearest neighbour in site Ly due to competition for resources, which implies a decline in microenvironment vitality. One possible explanation is that mutual exclusivity between bacterial communities caused by competition exists widely in the low-yield area, especially within similar niches. In addition, high-yield sites differed considerably from site Ly in terms of most members of Actinobacteria, Acidobacteria, and Planctomycetes. We infer that member of Acidobacteria and Actinobacteria had stronger adaptability and resilience, which enable their survival under stressful conditions [66], and regulated the surrounding environmental attributes through feedback mechanisms. The microbial community links showed more specific ecological significance than the physicochemical characteristics of farmland throughout the entire period of rice growth.

\section{Conclusion}

The results of the present study demonstrated that the gaps in crop yield are strongly associated with variations in the soil microbial communities during the heading stage, which were due to the effects of soil characteristic before transplanting; thus, in addition to adjusting the microhabitat before transplanting, there is the potential to improve the average crop yield by controlling rational 
agricultural management during the heading stage. In addition, the positive species interactions within communities may contribute to yield, as seen through network analysis, and the biological properties (i.e., microbes) better reflect real-world farmland situations than do physicochemical characteristics (i.e., nutrient elements). However, we have essentially focused on the relationships among soil characteristics and the variations and interactions of microbial communities. Hypotheses can be formed based on correlation analyses and need to be further tested to determine whether they are applicable to other land types.

\section{Additional file}

Additional file 1: Figure S1. Rarefaction curve of 16S rRNA gene sequencing at four sites (sites $\mathrm{Ha}, \mathrm{Hb}, \mathrm{HC}$ and Ly). Figure S2. Network constructed by the highest level (highly degree) of bacterial communities at site $\mathrm{Ha}$. Figure S3. Network constructed by the highest level (highly degree) of bacterial communities at site $\mathrm{Hb}$. Figure $\mathbf{S 4}$. Analysis of compositions and structures of bacterial communities from four groups.Table S1. Average yield of super hybrid rice "Y Liang You 900" at four sampling sites. Table S2. Name and batch of detected samples. Table S3. Mean value \pm

standard deviation $(n=3)$ for chemical properties of soils during the four periods . Table S4. Permutational multivariate analysis of variance (Adonis) shows the effects of soil properties at the various stages of crop transplanting on the yield of super rice using three methods. Table S5. Pearson positive correlations between crop yield and several physical and chemical soil

properties during the four stages of development. Table S6. Permutational multivariate analysis of variance (Adonis) shows the effect of bacterial diversity on crop yield at four stages of development. Table S7. Permutational multivariate analysis of variance (Adonis) shows the effect of bacterial community structure at the OUT level on crop yield at four stages of development. Table S8. Permutational multivariate analysis of variance (Adonis) shows the effect of bacterial community structure at the genus level on crop yield at four stages of development. Table S9. Relative abundances (\%) of the dominant bacterial phyla (a) and classes (b) in soil during heading stage. Table S10. Significant Pearson correlations between microbial community and soil environmental factors during the heading stage are shown at thephylum level. Table S11. Significant Pearson correlations between bacterial communities and soil environmental factors during the heading stage are shown at the genus level. (PDF $2493 \mathrm{~kb}$ )

\section{Abbreviations}

Adonis: Permutational multivariate analysis of variance; AN: available nitrogen; DCA: Detrended correspondence analysis; K: potassium; MEN: Molecular ecological network; P: Phosphorus; PLSPM: Partial leastsquares path; SOM: Soil organic matter; TN: Total nitrogen

\section{Acknowledgements}

We are grateful to the data analysis platform of Institute for Environmental Genomics.

\section{Funding}

The study was supported by the National Nature Science Foundation of China (No. 31371565, No. 31501698 and No. 41573072). The funding body made substantial contributions to design of the study and collection, analysis, and interpretation of data and in writing the manuscript.

\section{Availability of data and materials}

The entire 16S rRNA gene sequences were deposited in the NCBI database, and the accession number is SRP083104. The datasets used and/or analysed during the current study are available from the corresponding author on reasonable request.

\section{Authors' contributions}

$\mathrm{PL}, \mathrm{QL}$ and ZW: Design and conception of the experiment. ZL, DM, and HY Data analysis and manuscript preparation. WC, JS and ZG: Execution of the experiments. YL, JZ and HL: Participated in discussions and supervised overall experimental and theoretical works. All authors have read and approved the manuscript.

Ethics approval and consent to participate

Not applicable.

\section{Competing interests}

The authors declare that they have no competing interests.

\section{Publisher's Note}

Springer Nature remains neutral with regard to jurisdictional claims in published maps and institutional affiliations.

\section{Author details}

${ }^{1}$ Hunan Hybrid Rice Research Center/State Key Laboratory of Hybrid Rice, Changsha 410125, China. ${ }^{2}$ Hunan Institute of Microbiology, Changsha 410009, China. ${ }^{3}$ College of Plant Protection, Hunan Agricultural University, Changsha 410128, China. ${ }^{4}$ School of Minerals Processing and Bioengineering, Central South University, Changsha 410083, China. ${ }^{5}$ Hunan Soil and Fertilizer Institute, Changsha 410125, China. ${ }^{6}$ Hunan Institute of Agricultural Information and Engineering, Changsha 410125, China. 'LongPing Graduate Institute, Hunan University, Changsha 410125, China.

Received: 29 June 2017 Accepted: 3 April 2018

Published online: 04 June 2018

\section{References}

1. Berg G. Plant-microbe interactions promoting plant growth and health: perspectives for controlled use of microorganisms in agriculture. Appl Microbiol Biot. 2009:84(1):11-8.

2. Barea J. Future challenges and perspectives for applying microbial biotechnology in sustainable agriculture based on a better understanding of plant-microbiome interactions. J Soil Sci Plant Nut. 2015;15(2):261-82.

3. Larkin RP. Soil health paradigms and implications for disease management. Annu Rev Phytopathol. 2015;53:199-221.

4. Gunnell D, Eddleston M, Phillips MR, Konradsen F. The global distribution of fatal pesticide self-poisoning: systematic review. BMC Public Health. 2007;7(1):1.

5. Leach A, Mumford J. Pesticide environmental accounting: a method for assessing the external costs of individual pesticide applications. Environ Pollut. 2008:151(1):139-47.

6. Altieri MA. Linking ecologists and traditional farmers in the search for sustainable agriculture. Front Ecol Environ. 2004:2(1):35-42.

7. Lugtenberg B. Principles of plant-microbe interactions: microbes for sustainable agriculture: Springer; 2014.

8. Raaijmakers JM, Lugtenberg BJ. Perspectives for rhizosphere research. Molecular Microbial Ecology Of The Rhizosphere. 2013;1 \& 2:1227-32.

9. Egamberdieva D, Kamilova F, Validov S, Gafurova L, Kucharova Z, Lugtenberg B. High incidence of plant growth-stimulating bacteria associated with the rhizosphere of wheat grown on salinated soil in Uzbekistan. Environ Microbiol. 2008;10(1):1-9.

10. Berendsen RL, Pieterse CM, Bakker PA. The rhizosphere microbiome and plant health. Trends Plant Sci. 2012;17(8):478-86.

11. Uren NC. Types, amounts, and possible functions of compounds released into the rhizosphere by soil-grown plants. The rhizosphere Biochemistry and organic substances at the soil-plant interface Marcel Dekker, New York. 2007:1-21.

12. Singh BK, Millard P, Whiteley AS, Murrell JC. Unravelling rhizospheremicrobial interactions: opportunities and limitations. Trends Microbiol. 2004; 12(8):386-93.

13. Kennedy A, Smith K. Soil microbial diversity and the sustainability of agricultural soils. Plant Soil. 1995;170(1):75-86.

14. Kennedy A. Bacterial diversity in agroecosystems. Agric Ecosyst Environ. 1999;74(1):65-76.

15. Parkinson D, Coleman DC. Microbial communities, activity and biomass. Agric Ecosyst Environ. 1991;34(1-4):3-33. 
16. Smith RG, Gross KL, Robertson GP. Effects of crop diversity on agroecosystem function: crop yield response. Ecosystems. 2008;11(3):355-66.

17. Gans J, Wolinsky M, Dunbar J. Computational improvements reveal great bacterial diversity and high metal toxicity in soil. Science. 2005;309(5739):1387-90

18. Giller K, Beare M, Lavelle P, Izac A-M, Swift M. Agricultural intensification, soil biodiversity and agroecosystem function. Appl Soil Ecol. 1997;6(1):3-16.

19. Pankhurst C, Ophel-Keller K, Doube B, Gupta V. Biodiversity of soil microbial communities in agricultural systems. Biodivers Conserv. 1996:5(2):197-209.

20. Fragoso C, Brown G, Patrón J, Blanchart E, Lavelle P, Pashanasi B, Senapati B, Kumar T. Agricultural intensification, soil biodiversity and agroecosystem function in the tropics: the role of earthworms. Appl Soil Ecol. 1997;6(1):17-35.

21. Swift M, Anderson J. Biodiversity and ecosystem function in agricultural systems. In: Biodiversity and ecosystem function.: Springer; 1994. p. 15-41.

22. Øvreås L, Torsvik V. Microbial diversity and community structure in two different agricultural soil communities. MICROBIAL ECOL. 1998;36(3-4):303-15.

23. Stephen A, Karp DS, DeClerck F, Kremen C, Naeem S: Functional traits in agriculture: agrobiodiversity and ecosystem services. Trends in Ecology \& Evolution 2015, 30(9):531

24. Fuhrman JA. Microbial community structure and its functional implications. Nature. 2009;459(7244):193-9.

25. Lupwayi N, Rice W, Clayton G. Soil microbial diversity and community structure under wheat as influenced by tillage and crop rotation. Soil Biol Biochem. 1998;30(13):1733-41.

26. Whipps JM. Microbial interactions and biocontrol in the rhizosphere. J Exp Bot. 2001;52(suppl 1):487-511.

27. Thakore $Y$. The biopesticide market for global agricultural use. Ind Biotechnol. 2006;2(3):194-208.

28. Ehlers R-U. Einsatz der Biotechnologie im biologischen Pflanzenschutz. Schriftenreihe der Deutschen Phytomedizinischen Gesellschaft eV. 2006:8:17-31.

29. Chaparro JM, Sheflin AM, Manter DK, Vivanco JM. Manipulating the soil microbiome to increase soil health and plant fertility. Biology \& Fertility of Soils. 2012;48(5):489-99.

30. Edwards J, Johnson C, Santos-Medellín C, Lurie E, Podishetty NK, Bhatnagar S, Eisen JA, Sundaresan V. Structure, variation, and assembly of the rootassociated microbiomes of rice. P Natl Acad Sci. 2015;112(8):E911-20.

31. Peiffer JA, Spor A, Koren O, Jin Z, Tringe SG, Dangl JL, Buckler ES, Ley RE. Diversity and heritability of the maize rhizosphere microbiome under field conditions. P Natl Acad Sci. 2013;110(16):6548-53.

32. Bardgett RD, van der Putten WH. Belowground biodiversity and ecosystem functioning. Nature. 2014;515(7528):505-11.

33. Chen S, Zheng X, Wang D, Chen L, Xu C, Zhang X. Effect of long-term Paddyupland yearly rotations on Rice (Oryza sativa) yield, soil properties, and Bacteria community diversity. ScientificWorldJournal. 2012;2012(3):279641.

34. Smalla K, Wieland G, Buchner A, Zock A, Parzy J, Kaiser S, Roskot N, Heuer H, Berg G. Bulk and rhizosphere soil bacterial communities studied by denaturing gradient gel electrophoresis: plant-dependent enrichment and seasonal shifts revealed. Appl Environ Microb. 2001;67(10):4742-51.

35. Page AL: Methods of soil analysis. Part 2. Chemical and microbiological properties: American Society of Agronomy, soil science society of America; 1982.

36. Naumann K, Bassler R. Chemische Untersuchung von Futtermitteln: Neumann-Neudamm; 1976.

37. Zhao F, McGrath S, Crosland A. Comparison of three wet digestion methods for the determination of plant Sulphur by inductively coupled plasma atomic emission spectroscopy (ICP-AES). Commun Soil Sci Plan. 1994;25(34):407-18.

38. Jankauskas B, Slepetiene A, Jankauskiene G, Fullen MA, Booth CA. A comparative study of analytical methodologies to determine the soil organic matter content of Lithuanian Eutric Albeluvisols. Geoderma. 2006; 136(3):763-73.

39. Baker M, Stein JC, Wurgler J. When does the market matter? Stock prices and the investment of equity-dependent firms. In: National Bureau of Economic Research; 2002.

40. Tao J, Liu X, Liang Y, Niu J, Xiao Y, Gu Y, Ma L, Meng D, Zhang Y, Huang W. Maize growth responses to soil microbes and soil properties after fertilization with different green manures. Appl Microbiol Biot. 2016;101(3):1-11.

41. Yin H, Niu J, Ren Y, Cong J, Zhang X, Fan F, Xiao Y, Zhang X, Deng J, Xie M. An integrated insight into the response of sedimentary microbial communities to heavy metal contamination. Sci Rep-Uk. 2015;5(1):14266

42. Magoč T, Salzberg SL. FLASH: fast length adjustment of short reads to improve genome assemblies. Bioinformatics. 2011;27(21):2957-63.
43. Edgar RC, Haas BJ, Clemente JC, Christopher Q, Rob K. UCHIME improves sensitivity and speed of chimera detection. Bioinformatics. 2011;27(16): 2194-200.

44. Edgar RC. Search and clustering orders of magnitude faster than BLAST. Bioinformatics. 2010;26(19):2460-1.

45. Melendrez MC, Lange RK, Cohan FM, Ward DM. Influence of molecular resolution on sequence-based discovery of ecological diversity among Synechococcus populations in an alkaline siliceous hot spring microbial mat. Appl Environ Microb. 2011;77(4):1359-67.

46. Cole JR, Wang Q, Fish JA, Chai B, McGarrell DM, Sun Y, Brown CT, PorrasAlfaro A, Kuske CR, Tiedje JM: Ribosomal Database Project: data and tools for high throughput rRNA analysis. NUCLEIC ACIDS RES 2013:gkt1244.

47. Team RC: R: a language and environment for statistical Computing 2013.

48. Sanchez G, Trinchera L: plspm: Partial Least Squares data analysis methods. R package version 02-2. URL: http://CRANR-project.org/package=plspm 2012.

49. Zhou J, Deng Y, Luo F, He Z, Tu Q, Zhi X. Functional molecular ecological networks. MBio. 2010;1(4):1592-601.

50. Ye D, Jiang $Y H$, Yang $Y$, He Z, Feng L, Zhou J. Molecular ecological network analyses. Bmc Bioinformatics. 2012;13(1):113.

51. Wang H, Wei Z, Mei L, Gu J, Yin S, Faust K, Raes J, Deng Y, Wang Y, Shen Q. Combined use of network inference tools identifies ecologically meaningful bacterial associations in a paddy soil. Soil Biol Biochem. 2017:105:227-35.

52. Zhang Y, Zhao Z, Dai M, Jiao N, Herndl GJ. Drivers shaping the diversity and biogeography of total and active bacterial communities in the South China Sea. Mol Ecol. 2014;23(9):2260-74.

53. Bakker MG, Manter DK, Sheflin AM, Weir TL, Vivanco JM. Harnessing the rhizosphere microbiome through plant breeding and agricultural management. Plant Soil. 2012;360(1-2):1-13.

54. Philippot L, Spor A, Hénault C, Bru D, Bizouard F, Jones CM, Sarr A, Maron PA. Loss in microbial diversity affects nitrogen cycling in soil. Isme J. 2013;7(8):1609.

55. Berg G, Smalla K. Plant species and soil type cooperatively shape the structure and function of microbial communities in the rhizosphere. FEMS Microbiol Ecol. 2009:68(1):1-13.

56. An M, Zhou X, Wu F, Ma Y, Yang P. Rhizosphere soil microorganism populations and community structures of different watermelon cultivars with differing resistance to fusarium oxysporum f. Sp. niveum. Can J Microbiol. 2011:57(5):355-65.

57. Cornell HV, Lawton JH. Species interactions, local and regional processes, and limits to the richness of ecological communities: a theoretical perspective. J Anim Ecol. 1992;61(1):1-12.

58. Thébault $\mathrm{E}$, Loreau M: Trophic interactions and the relationship between species diversity and ecosystem stability. Am Nat 2005, 166(Volume 166 Number 4):E95-114.

59. Creer S, Sinniger F. Cosmopolitanism of microbial eukaryotes in the global deep seas. Mol Ecol. 2012;21(5):1033-5.

60. Ryu C, Suguri M, Umeda M. Multivariate analysis of nitrogen content for rice at the heading stage using reflectance of airborne hyperspectral remote sensing. Fuel \& Energy Abstracts. 2011;122(3):214-24.

61. García-Orenes F, Morugán-Coronado A, Zornoza R, Scow K. Changes in soil microbial community structure influenced by agricultural management practices in a Mediterranean agro-ecosystem. PLoS One. 2013;8(11):e80522.

62. Niu J, Rang Z, Zhang C, Chen W, Tian F, Yin H, Dai L. The succession pattern of soil microbial communities and its relationship with tobacco bacterial wilt. BMC Microbiol. 2016;16(1):233.

63. Lauber CL, Hamady M, Knight R, Fierer N. Pyrosequencing-based assessment of soil pH as a predictor of soil bacterial community structure at the continental scale. Appl Environ Microb. 2009:75(15):5111-20.

64. Bruce T, Martinez IB, Neto OM, Vicente ACP, Kruger RH, Thompson FL. Bacterial community diversity in the Brazilian Atlantic forest soils. MICROBIAL ECOL. 2010;60(4):840-9.

65. Brussaard L, De Ruiter PC, Brown GG. Soil biodiversity for agricultural sustainability. Agric Ecosyst Environ. 2007;121(3):233-44.

66. Trivedi P, Anderson IC, Singh BK. Microbial modulators of soil carbon storage: integrating genomic and metabolic knowledge for global prediction. Trends Microbiol. 2013:21(12):641-51. 